\title{
Universiteit
}

Leiden

The Netherlands

\section{Classroom-evaluated school performance at nine years of age after very preterm birth}

Jansen, L.; Peeters-Scholte, C.; Wiggers-de Bruine, S.; Berg-Huysmans, A. van den; Klink, J. van; Steenis, A. van; ... ; Steggerda, S.

\section{Citation}

Jansen, L., Peeters-Scholte, C., Wiggers-de Bruine, S., Berg-Huysmans, A. van den, Klink, J. van, Steenis, A. van, ... Steggerda, S. (2020). Classroom-evaluated school performance at nine years of age after very preterm birth. Early Human Development, 140.

doi:10.1016/j.earlhumdev.2019.104834

Version: $\quad$ Accepted Manuscript

License: $\quad$ Leiden University Non-exclusive license

Downloaded from: https://hdl.handle.net/1887/3181419

Note: To cite this publication please use the final published version (if applicable). 


\title{
Classroom-evaluated school performance at nine years of age after very preterm birth ${ }^{\text {मे }}$
}

\author{
Lisette Jansen $^{\mathrm{a}, *}$, Cacha Peeters-Scholte ${ }^{\mathrm{b}}$, Sica Wiggers-de Bruine ${ }^{\mathrm{c}}$, \\ Annette van den Berg-Huysmans ${ }^{\mathrm{c}}$, Jeanine van Klink ${ }^{\mathrm{a}}$, Andrea van Steenis ${ }^{\mathrm{d}}$, Monique Rijken ${ }^{\mathrm{d}}$, \\ Robert Vermeiren ${ }^{\mathrm{e}}$, Sylke Steggerda ${ }^{\mathrm{d}}$
}

${ }^{a}$ Department of Medical Psychology, Leiden University Medical Center, the Netherlands

${ }^{\mathrm{b}}$ Department of Neurology, Leiden University Medical Center, the Netherlands

${ }^{\mathrm{c}}$ Department of Radiology, Leiden University Medical Center, the Netherlands

${ }^{\mathrm{d}}$ Department of Neonatology, Leiden University Medical Center, the Netherlands

${ }^{\mathrm{e}}$ Department of Child and Adolescent Psychiatry, University Medical Center, Curium, Leiden, the Netherlands

\section{A R T I C L E I N F O}

\section{Keywords:}

Preterm

Premature birth

School performance

Brain injury

Perinatal risk factors

Special education

MRI

\begin{abstract}
A B S T R A C T
Objective: To determine classroom-evaluated school performance nine years after preterm birth, predicted by perinatal risk factors and neonatal brain abnormalities.

Study design: Children were recruited from a consecutive cohort of 113 preterm infants ( $<32$ weeks' gestation), participating in a longitudinal prospective study, investigating brain injury and neurodevelopmental outcome. Data on perinatal risk factors, presence of brain injury at term-equivalent age, and maternal education were collected. Information on school performance included enrollment in special (primary) education, grade repetition and school results from the nationwide standardized Dutch Pupil Monitoring System regarding reading comprehension, spelling, and mathematics.

Results: Information on school enrollment was available for 87 children (77\%), of whom 7 (8\%) were in special primary education and $19(22 \%)$ repeated a grade. This was significantly higher compared to national rates $(p \leq .05)$. Results on school performance were available for 74 children $(65 \%)$ and showed clearly below average scores in reading comprehension $(p=.006)$, spelling $(p=.014)$ and mathematics $(p<.001)$. Univariate analysis showed that lower performance in reading comprehension was predicted by male sex and low maternal education; spelling by male sex; and mathematics by Bronchopulmonary Dysplasia, white matter injury and maternal education. In a multivariate model, male sex and maternal education were predictive for reading comprehension and white matter injury for mathematics.

Conclusion: Preterm born children more often need special primary education and have higher grade repeat rates. They perform poorer on reading comprehension, spelling and mathematics. Regular follow-up remains important for preterm born children during school age.
\end{abstract}

\section{Introduction}

About half of preterm born children suffer from academic difficulties [1]. Because of this vulnerability, preterm born children are almost three times more likely to receive any form of special education assistance [2]. This can have important consequences as academic performance is associated with long-term health and life chances [3]. A major question for parents of a preterm infant is whether their child will be able to follow a regular educational trajectory. However, studies investigating the relation between classroom-evaluated school performance and perinatal factors are scarce.

Recent studies assessing academic performance have found lower achievements in reading and spelling, and in particular in mathematics in extreme preterm $(<28$ weeks' gestational age (GA)) born children [4]. Academic functioning in children is mainly assessed by the use of standardized achievement tests, administered in a clinically controlled

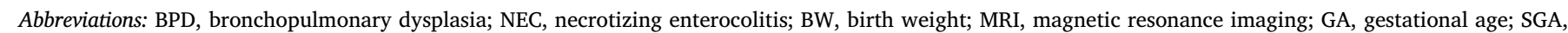
small for gestational age; IQ, Intelligence Quotient; TEA, term equivalent age; CBS, Central Bureau for Statistics; SD, Standard Deviation

Funding: This work was supported by Chiesi Ltd.

* Corresponding author at: Department of Medical Psychology, Leiden University Medical Center, J6-S, Albinusdreef 2, 2333 ZA Leiden, the Netherlands.

E-mail address: 1.jansen.psy@lumc.nl (L. Jansen). 
one-on-one environment. The results can therefore hardly be compared with school performance achieved in a regular classroom, where other conditions such as concentration and motivation are of great importance. Studies that did use other methods to assess academic performance were inconclusive on the performance in reading comprehension and spelling, but did find poorer performances in mathematics in preterm children $[5,6]$.

Several perinatal factors, preterm brain injury and maternal education are known to influence long-term cognitive development in children born preterm [7]. Their relation to classroom-evaluated school performance is however still unclear. One of the reasons is the diversity in educational testing between schools. In the Netherlands, however, due to the use of nationwide standardized testing, we have the unique possibility to assess actual educational attainment at school. The aim of this study was therefore to describe school performance, as assessed in a regular classroom, in a cohort of children nine years after preterm birth in relation to perinatal risk factors, brain abnormalities on neonatal magnetic resonance imaging (MRI) and maternal education.

\section{Methods}

\subsection{Participants}

This study was performed as part of a larger single-center longitudinal prospective study on neuroimaging and outcome after preterm birth. Participants were part of an unselected cohort of 113 very preterm born children (GA $<32$ weeks) who were admitted to the tertiary neonatal unit of our hospital between May 2006 and November 2007. Preterm children were eligible when they had no congenital abnormalities, metabolic disorders or neonatal meningitis. All children underwent serial neonatal ultrasound scans according to protocol and MRI at term equivalent age (TEA) and were invited for follow-up visits with standardized neurodevelopmental assessment at two and nine years of age. Data on neonatal brain imaging findings and outcome at two years of age in this cohort have been published previously [8-11]. The institutional review board approved this prospective study and parental consent was obtained.

\subsection{Outcome assessment}

\subsubsection{School enrollment and performance}

Parents and teachers of the participating children were asked to fill in questionnaires on the attendance of mainstream primary education, special education or special primary education and grade repetition. Special education in the Netherlands is intended for children with severe visual impairments (cluster 1), children with severe hearing impairments, problems with speech and communication (cluster 2), physical or mental retardation and learning difficulties (cluster 3) and children with severe behavioral and/or psychiatric problems (cluster 4). Special primary education is intended for children with milder special educational needs, who are falling behind in mainstream education, but do not meet the criteria for special education. It is characterized by smaller classes and less distraction compared to mainstream education. In order to compare the results of the preterm children to their Dutch peers, reference data according to the Dutch Central Bureau for Statistics (CBS) on enrollment in special (primary) education during the school year 2015/2016 were used [12]. Most children in our study population were in 2015/2016 in the third grade (year five) of primary school.

Within the Netherlands, almost all children (98\%) start their school career at age four [13]. During the first two years, children attend preschool. They start with the first year of primary school in August after they turned six between October of the previous year and the following September. Some children are not ready to continue to the first grade of primary school (third year), due to social or emotional immaturity [6]. These children will repeat the second year of preschool.
Grade repetition also occurs if a child cannot keep up with its peers during primary school. In order to compare grade repeat rates with Dutch peers, reference data according to the CBS on grade repetition in 2015 were used [14].

Data on school performance were obtained directly from the children's schools. Dutch elementary schools regularly follow the learning achievements of children by administering standardized school achievement tests, according to the National Institute for Educational Measurements [15]. The Dutch National Pupil Monitoring System is designed to compare the level of an individual child to their own developmental trajectory and to their age matched peers within the Dutch population. The tests start in the second year of primary school at age 5 and are administered at specific time points during the school year. Raw tests scores are converted into ability scores and based on these ability scores, children are categorized in five levels, level A through E. Level A contains the 25\% highest performing Dutch children, level B the other $25 \%$ of children who also perform above average, level $C$ the $25 \%$ who perform slightly below average, level D the $15 \%$ of children performing clearly below average and level $\mathrm{E}$ are the $10 \%$ lowest performing children. For this study, the test results at the end of the third grade were obtained for reading comprehension, spelling and mathematics.

\subsubsection{School performance in relation to perinatal risk factors, brain injury and maternal education}

To investigate whether subgroups of preterm infants were more likely to develop problems in later school performance relevant perinatal and maternal data from the original database were obtained and neonatal MRI scans were reviewed. Perinatal risk factors included the child's sex, GA at birth, small for gestational age (SGA), postnatal sepsis, necrotizing enterocolitis (NEC) and bronchopulmonary dysplasia (BPD). SGA was based on a birth weight below the 10th percentile [16]. Postnatal sepsis with a positive blood culture and/or NEC $\geq$ stage 2 [17] were taken together as one variable (sepsis and/or NEC). BPD was categorized as none or mild/moderate/severe BPD according to Banclari (2006). To determine the presence and severity of brain injury all neonatal MRI scans were reviewed by at least two experienced investigators (SS, FWB, AvS, TM), using the cerebral white matter and cerebellar abnormality scores of a standardized MR imaging scoring system [18]. The investigators had no knowledge of any clinical characteristics or outcome data of the children except the GA at the time of scanning. The severity of white matter and cerebellar injury was categorized as normal versus mild versus moderate/severe. Maternal education was classified as low (primary school and lower general secondary school), intermediate, or high level (higher vocational school and university) of education [19].

\subsection{Statistical analysis}

Statistical analyses were conducted using SPSS (version 23.0 IBM, Armonk, NY, USA). Descriptive results for nominal variables were presented as number of cases and percentages. Means and standard deviations (SD) were reported for continuous variables. Binomial tests for proportions were conducted to compare the percentage of children in special (primary) education, the grade repetition rate and the percentages of children in each level of school performance to their Dutch peers. To investigate the relation between perinatal factors, neonatal brain injury, maternal education and school performance, children were categorized in two groups: the lowest categories of school performance (level D and E) versus the average and higher categories of school performance (level A, B and C). Binary logistic univariate regressions were conducted to study potential risk factors for school performance on reading comprehension, spelling and mathematics. Secondly, variables from the univariate analysis with a $p$-value of $<.05$ were included into a multivariate regression model. To adjust for the effect that observations in twins are not independent, the multivariate 
Table 1

Perinatal characteristics and level of maternal education of the study population.

\begin{tabular}{|c|c|}
\hline Perinatal characteristics & Participants $(\mathrm{N}=87)$ \\
\hline Male sex (\%) & $50(58 \%)$ \\
\hline Part of twins or triplets (\%) & $31(36 \%)$ \\
\hline GA (weeks), mean \pm SD & $28.94 \pm 2.0$ \\
\hline BW $(g)$, mean $\pm S D$ & $1204 \pm 359$ \\
\hline SGA (\%) & $10(12 \%)$ \\
\hline \multicolumn{2}{|l|}{ BPD (\%) } \\
\hline None & $47(54 \%)$ \\
\hline Mild & $17(20 \%)$ \\
\hline Moderate & $22(25 \%)$ \\
\hline Severe & $1(1 \%)$ \\
\hline Sepsis (\%) & $32(37 \%)$ \\
\hline Necrotizing enterocolitis (\%) & $3(3 \%)$ \\
\hline \multicolumn{2}{|l|}{ White matter injury } \\
\hline Normal & $46(54 \%)$ \\
\hline Mild & $18(21 \%)$ \\
\hline Moderate & $14(16 \%)$ \\
\hline Severe & $8(9 \%)$ \\
\hline \multicolumn{2}{|l|}{ Cerebellar injury } \\
\hline Normal & $65(76 \%)$ \\
\hline Mild & $11(13 \%)$ \\
\hline Moderate & $4(4 \%)$ \\
\hline Severe & $6(7 \%)$ \\
\hline \multicolumn{2}{|l|}{ Maternal education } \\
\hline Low (\%) & $20(23 \%)$ \\
\hline Intermediate (\%) & $30(35 \%)$ \\
\hline High (\%) & $37(42 \%)$ \\
\hline
\end{tabular}

$\mathrm{GA}=$ Gestational age, $\mathrm{BW}=$ Birth Weight, $\mathrm{SGA}=$ Small for Gestational Age, $\mathrm{BPD}=$ Bronchopulmonary dysplasia, $\mathrm{SD}=$ Standard Deviation.

analyses were conducted in a generalized estimated equations model [20]. To adjust for multiple comparisons of the three outcome variables, reading comprehension, spelling and mathematics, a $p$-value of $<.017(0.05 / 3)$ was seen as statistically significant.

\section{Results}

Information on school enrollment and grade repetition was available in 87 (77\%) of the 113 children. Reasons for loss to follow-up were refusal by parents/child $(n=10)$, moved abroad $(n=9)$ and loss of contact $(n=7)$. Of one child, data on perinatal factors and information on school enrollment and school performance were available, but the MRI at TEA data were missing and therefore could not be reviewed. There were no differences in perinatal factors, severity of brain injury or level of maternal education between children with or without followup. Table 1 shows the characteristics of the study population.

\subsection{School enrollment and performance compared to the general population of Dutch peers}

Table 2 displays the outcomes on school enrollment. Overall, $87 \%$ $(76 / 87)$ of the preterm children were enrolled in mainstream primary education. Eight percent (7/87) were enrolled in special primary
Table 3

Academic performance based on the Dutch Pupil Monitoring System.

\begin{tabular}{|c|c|c|c|}
\hline & $(\mathrm{n}=74)$ & Dutch population & $p$ \\
\hline \multicolumn{4}{|c|}{ Reading comprehension } \\
\hline A & $23(31 \%)$ & $25 \%$ & .142 \\
\hline B & $11(15 \%)$ & $25 \%$ & .025 \\
\hline C & $11(15 \%)$ & $25 \%$ & .025 \\
\hline D & $14(19 \%)$ & $15 \%$ & .198 \\
\hline $\mathrm{E}$ & $15(20 \%)$ & $10 \%$ & .006 \\
\hline \multicolumn{4}{|l|}{ Spelling } \\
\hline A & $19(26 \%)$ & $25 \%$ & .464 \\
\hline B & $15(20 \%)$ & $25 \%$ & .232 \\
\hline C & $18(24 \%)$ & $25 \%$ & .509 \\
\hline D & $8(11 \%)$ & $15 \%$ & .215 \\
\hline $\mathrm{E}$ & $14(19 \%)$ & $10 \%$ & .014 \\
\hline \multicolumn{4}{|c|}{ Mathematics } \\
\hline A & $14(19 \%)$ & $25 \%$ & .155 \\
\hline B & $11(15 \%)$ & $25 \%$ & .029 \\
\hline C & $18(24 \%)$ & $25 \%$ & .536 \\
\hline D & $11(15 \%)$ & $15 \%$ & .534 \\
\hline $\mathrm{E}$ & $20(27 \%)$ & $10 \%$ & .000 \\
\hline
\end{tabular}

education, which is significantly higher compared to the $2.4 \%$ of children who are enrolled in special primary education throughout the Netherlands $(p=.005)$. Five percent $(4 / 87)$ of the preterm children were enrolled in special education, which is comparable to their Dutch peers. Within the group of children who enrolled in mainstream education, $24 \%(18 / 76)$ received additional assistance in the classroom, mostly through remedial teaching.

The percentage of children who repeated a grade, in both mainstream and special education, was $22 \%(19 / 87)$. This is a significant higher number $(p=.000)$ compared to the $7.4 \%$ of children within the Dutch population who repeat a grade in primary school until grade 3 (year 5). Differentiating between mainstream and special (primary) education, $20 \%(15 / 76)$ of the preterm children in mainstream education repeated a grade, and $36 \%(4 / 11)$ of the children in special (primary) education. Most children, 74\% (14/19), repeated the second year of preschool education. In first grade, $21 \%(4 / 19)$ of the children had to repeat a grade and $5 \%(1 / 19)$ in second grade.

Results of the nationwide standardized achievement tests were available for 74 (65\%) children, following regular and special (primary) education, of the initial cohort. Table 3 shows that preterm children more often performed within the lowest category (E) in reading comprehension, spelling and mathematics, compared to the $10 \%$ of their Dutch peers. In reading comprehension, $20 \%(15 / 74)$ of the children performed in level E $(p=.006)$; in spelling, 19\% $(14 / 74, p=.014)$, and in mathematics $27 \%(20 / 74, p=.000)$.

\subsection{School performance in relation to perinatal risk factors, brain injury} and maternal education

Univariate regression analysis (Table 4) showed that sex $(\mathrm{B}=-1.368, p=.009)$ and level of maternal education $(\mathrm{B}=-2.351$, $p=.000)$ both predicted the performance on reading comprehension. Males performed worse than females and children of mothers with a

Table 2

School enrollment of the 87 children included for follow-up.

\begin{tabular}{lll}
\hline & $\begin{array}{l}\text { Study population } \\
(\mathrm{n}=87)\end{array}$ & Dutch population \\
\hline Appropriate grade for age, without support (\%) & $43(48 \%)$ & \\
Appropriate grade for age, with support (\%) & $18(20 \%)$ & $7.40 \%$ \\
One or more grades below (\%) & $19(22 \%)$ & \\
$\quad$ Grade repetition in preschool & $14(74 \%)$ & .000 \\
Grade repetition in grade 1/2 & $5(26 \%)$ & $4.73 \%$ \\
Special education (\%) & $4(5 \%)$ & $2.41 \%$ \\
Special primary education (\%) & $7(8 \%)$ & .879 \\
\hline
\end{tabular}


Table 4

Univariate analysis, factors affecting school performance.

\begin{tabular}{|c|c|c|c|c|c|c|}
\hline & \multicolumn{2}{|c|}{ Reading comprehension } & \multicolumn{2}{|l|}{ Spelling } & \multicolumn{2}{|c|}{ Mathematics } \\
\hline & B & $p$ & B & $p$ & B & $p$ \\
\hline Male sex & -1.368 & .009 & -1.658 & .007 & -0.551 & .254 \\
\hline GA at birth & 0.063 & .609 & 0.089 & .497 & 0.214 & .086 \\
\hline SGA & 0.495 & .510 & 0.942 & .223 & 0.395 & .612 \\
\hline BPD & 0.106 & .825 & 0.128 & .803 & 1.054 & .031 \\
\hline Sepsis/NEC & .345 & .483 & .811 & .120 & .885 & .074 \\
\hline \multicolumn{7}{|l|}{ White matter injury } \\
\hline Normal - moderate/severe & 0.241 & .680 & 1.076 & .075 & 1.856 & .003 \\
\hline Mild - moderate/severe & -0.922 & .217 & 0.588 & .443 & -0.118 & .880 \\
\hline \multicolumn{7}{|l|}{ Cerebellar injury } \\
\hline Normal - moderate/severe & 0.799 & .325 & 1.293 & .115 & 1.504 & .088 \\
\hline Mild- moderate/severe & 0.693 & .488 & 1.674 & .128 & 0.511 & .629 \\
\hline \multicolumn{7}{|l|}{ Maternal education } \\
\hline Low - high & -2.351 & .000 & -1.099 & .087 & -1.181 & .047 \\
\hline Intermediate - high & -1.216 & .054 & -1.019 & .110 & -1.076 & .066 \\
\hline
\end{tabular}

$\mathrm{GA}=$ Gestational age, $\mathrm{BPD}=$ Bronchopulmonary dysplasia, $\mathrm{SGA}=$ Small for Gestational Age, NEC = Necrotizing enterocolitis

high level of education performed better. Males also had a poorer performance in spelling $(\mathrm{B}=-1.658, p=.007)$. A poorer performance in mathematics was predicted by the absence of $\mathrm{BPD}(\mathrm{B}=1.054$, $p=.031$ ), presence of moderate/severe white matter injury on neonatal MRI ( $\mathrm{B}=1.856, p=.003)$ and a lower level of maternal education $(\mathrm{B}=-1.181, p=.000)$.

Tables $5 \mathrm{a}$ and $5 \mathrm{~b}$ show the results of the multivariate regression analysis for reading comprehension and mathematics. No multivariate regression analysis was conducted for spelling, as only sex showed an effect in the univariate analysis. Both male sex $(\mathrm{B}=-1.773, p=.004)$ and a low level of maternal education $(\mathrm{B}=-2.737, p=.000)$ remained independent predictors for a lower performance in reading comprehension. The presence of moderate/severe white matter injury ( $\mathrm{B}=1.601, p=.013$ ) remained an independent predictor for mathematics. The presence of BPD and level of maternal education did no longer have a significant effect on the performance in mathematics. Correction for multiple testing did not affect these results.

\section{Discussion}

This is, to our knowledge, the first study investigating classroomevaluated school performance in a prospective cohort of very preterm children in relation to perinatal factors, brain injury and maternal education. Other similar studies mostly reported on academic performance as evaluated in a clinically controlled one-one-one environment or based on individual information reported by parents or teachers instead of using standardized tests in a school setting. School performance is more than being able to comply with tasks, it is also about being able to focus in a classroom full of distraction and being able to motivate yourself. Results of the few studies that did include classroomevaluated school performance were inconclusive on performance in reading comprehension and spelling, but found poorer performances of preterm born children in mathematics. It has been known that birth weight and gestational age are associated with cognitive and academic

Table 5a

Multivariate regression analysis, reading comprehension.

\begin{tabular}{lcc}
\hline & \multicolumn{2}{l}{ Reading comprehension } \\
\cline { 2 - 3 } & $\mathrm{B}$ & \multirow{2}{*}{${ }^{*} .004$} \\
\hline Male sex & -1.773 & \\
Maternal education & & \\
$\quad$ Low - high & -2.737 & ${ }^{*} .000$ \\
Intermediate - high & -1.247 & .069 \\
\hline
\end{tabular}

* p-value $<.05$.
Table 5b

Multivariate regression analysis, mathematics.

\begin{tabular}{llc}
\hline & \multicolumn{2}{l}{ Mathematics } \\
\cline { 2 - 3 } & $\mathrm{B}$ & $p$ \\
\hline BPD & -0.579 & .328 \\
White matter injury & 1.601 & .013 \\
$\quad$ Normal - moderate/severe & -0.044 & .959 \\
$\quad$ Mild - moderate/severe & -1.113 & .107 \\
Maternal education & -0.655 & .310 \\
$\quad$ Low - high & Intermediate - high & \\
\hline
\end{tabular}

$\mathrm{BPD}=$ Bronchopulmonary dysplasia.

outcomes. However, the relation between other perinatal factors, neonatal brain injury, maternal education and classroom-evaluated school performance has remained unknown.

Within our study population, a high number of preterm infants was enrolled in special primary education. This is in line with the results from other studies [7]. However, the number of children enrolled in special education, in other words, the children with severe hearing or visual impairments, learning disabilities of psychiatric disorders, was not higher compared to the general population. Within The Netherlands, the indications for special education are strict, the child's impairment or learning disability needs to be severe. Also, in 2014 the Education that Fits Act was introduced in The Netherlands, with the purpose of keeping more children with special educational needs in mainstream primary education. This has raised the threshold for children to be referred to special education [21]. In 2014, most children in our study population reached the age of seven and were enrolled in primary school. The higher threshold therefore also applied to them. This may have led to the relative high percentage $(24 \%)$ of children with additional support in mainstream education within our study population. However, most children (87\%) in our study population followed mainstream education, either with or without additional support or grade repetition.

Besides a higher need for special primary education, there was a higher grade repetition rate for the preterm children within our study population. The majority of these children repeated a grade in preschool, because it was considered that they were not ready for primary school. Within the Netherlands, a relatively high number of children (approximately 10\%) repeat a year in preschool [22]. In our study cohort, the percentage of children who repeated a grade in preschool was $16 \%(14 / 87)$.

Looking at school performance, the preterm born children in our 
study population had lower performances in reading comprehension, spelling and mathematics, with the biggest proportion of preterm children experiencing difficulties in mathematics. Already in preschool, before the age of six, it is noticed that preterm born children have more difficulties with numerical reasoning skills [6]. Mathematical difficulties are associated with poorer internal representation of numbers, which starts early on in life [23]. It is also known that impaired executive functioning is an important predictor for poor mathematical performance in primary school, but not (already) in preschool [24]. Possibly this is due to the fact that the mathematical problems that children face become more complex and are in need of a higher level of neurocognitive abilities in order to solve them. Contrary to the early findings of difficulties in numerical reasoning skills, preterm born children do well in early linguistics in preschool [6]. However, this had in our study population no positive effect on their performance in reading comprehension and spelling.

Within the general population, there are some established factors influencing school performance, such as sex and maternal education. Studies have shown that there is a sex difference favoring girls in reading and writing achievement, possibly relating to early advantages in various language-related skills and therefor facilitating the learning process of how to read and write [25]. Maternal education within the general population is an established factor influencing IQ, executive functioning and, therefore, school performance [26]. In our study population, male sex was predictive of a lower performance in reading comprehension and spelling and a lower level of maternal education predicted a poorer performance in reading comprehension.

Some factors are known to influence neurocognitive outcome after preterm birth, like birth weight and GA [27]. The influence of other factors, such as the impact of neonatal brain injury, is still unclear, ranging from limited predictive value of white matter injury for neurocognitive and behavioral impairment [28], to the prediction of cognitive delay by white matter abnormalities [29]. GA was not a predictor of poor school performance in our study population, possibly due to the restricted range of GA [30]. Neonatal moderate/severe white matter injury was predictive of a lower performance on mathematics.

There is still a substantial unexplained residual variance when it comes to predicting school performance [31]. Literature has identified many variables that (might) influence school grades, such as factors concerning the child itself, the quality of education and parental upbringing. This suggests that there are multiple ways of facilitating cognitive development, despite the conditions in which a child is born.

\subsection{Limitations}

This study has limitations, one of them being the lack of reference data collected from a term-born control group, matched for example on socioeconomic status based on the level of maternal education. However, we did have reference data of the general population of Dutch peers. We experienced a relatively high loss to follow-up, due to the seven year gap between the previous follow-up at two years of age and this study's assessment. Because of the relative small number of children, some associations might be less visible.

We conclude that more than half of preterm born children need extra assistance in primary school, either through support in the classroom, grade repetition or enrollment in special primary education. Sex, white matter injury and maternal education were predictive of school performance. Nearly half of the children struggled with mathematical performance. Given the growing evidence that preterm born children already lag behind in their numerical reasoning skills in preschool, it is important that these children are carefully watched and offered additional support. Future research should therefore focus on the development of intervention programs that may help parents and teachers to support preterm born children on (pre)academic areas and on the role of other factors possibly influencing academic performance, such as parenting style and underlying dysfunctions.

\section{Funding}

S.J. Steggerda received a grand from Chiesi Ltd. for the PROUD study (PReterm brain injury, long-term OUtcome and brain Development study).

\section{Declaration of competing interest}

None.

\section{Acknowledgement}

We would like to thank Romy Berkhout for her support during the study, Rianne Ellens and Carolien Kerkhoven for their participation in collecting the data and Tamara Meulman for her help reviewing the neonatal MRI scans.

\section{References}

[1] P. Anderson, L.W. Doyle, S. Victorian, Infant collaborative, neurobehavioral outcomes of school-age children born extremely low birth weight or very preterm in the 1990s, Jama-Journal of the American Medical Association 289 (24) (2003) 3264-3272.

[2] E.S. Twilhaar, et al., Academic performance of children born preterm: a metaanalysis and meta-regression, Arch Dis Child Fetal Neonatal Ed 103 (4) (2018) F322-F330.

[3] L.W. Doyle, P.J. Anderson, Adult outcome of extremely preterm infants, Pediatrics 126 (2) (2010) 342-351.

[4] N. Akshoomoff, et al., Academic achievement deficits and their neuropsychological correlates in children born extremely preterm, J. Dev. Behav. Pediatr. 38 (8) (2017) 627-637.

[5] I. Kirkegaard, et al., Gestational age and birth weight in relation to school performance of 10-year-old children: a follow-up study of children born after 32 completed weeks, Pediatrics 118 (4) (2006) 1600-1606.

[6] C.S.H. Aarnoudse-Moens, et al., Development of preschool and academic skills in children born very preterm, J. Pediatr. 158 (1) (2011) 15-20.

[7] E.S. Twilhaar, et al., Cognitive outcomes of children born extremely or very preterm since the 1990s and associated risk factors a meta-analysis and meta-regression, JAMA Pediatr. 172 (4) (2018) 361-367.

[8] L.M. Leijser, et al., Brain imaging findings in very preterm infants throughout the neonatal period: part I. incidences and evolution of lesions, comparison between ultrasound and MRI, Early Hum. Dev. 85 (2) (2009) 101-109.

[9] F.T. de Bruine, et al., Clinical implications of MR imaging findings in the white matter in very preterm infants: a 2-year follow-up study, Radiology 261 (3) (2011) 899-906.

[10] F.T. De Bruine, et al., Tractography of white-matter tracts in very preterm infants: a 2-year follow-up study, Dev. Med. Child Neurol. 55 (5) (2013) 427-433.

[11] S.J. Steggerda, et al., Small cerebellar hemorrhage in preterm infants: perinatal and postnatal factors and outcome, Cerebellum 12 (6) (2013) 794-801.

[12] CBS, https://opendata.cbs.nl/\#/CBS/nl/dataset/71478ned/table?ts= 1558689469849. Den Haag, the Netherlands, 2016 (accessed 21 May 2019).

[13] v., B. Leeuwen, A. Thijs, M. Zandbergen, Inclusive Education in the Netherlands, SLO, Enschede, 2008.

[14] CBS, https://www.onderwijsincijfers.nl/kengetallen/po/leerlingen-po/prestaties verblijfsduur. Den Haag, the Netherlands, 2015 (accessed 21 May 2019).

[15] J. Hollenberg, M. van der Lubbe, Toetsen op School. Primair Onderwijs, Cito Corporate, Arnhem, 2012.

[16] L. Hoftiezer, et al., From population reference to national standard: new and improved birthweight charts, Am. J. Obstet. Gynecol. 220 (4) (2019).

[17] M.J. Bell, J.L. Ternberg, R.D. Feigin, et al., Neontal necrotizing enterocolitis. Therapeutic decisions based upon clinical staging, Ann. Surg. 187 (1978) 1-7.

[18] H. Kidokoro, J.J. Neil, T.E. Inder, New MR imaging assessment tool to define brain abnormalities in very preterm infants at term, Am. J. Neuroradiol. 34 (11) (2013) 2208-2214 2014

[19] CBS, Standaard onderwijsindeling 2016, Centraal Bureau voor de Statistiek, Den Haag, 2016.

[20] A.M. Hibbs, et al., Accounting for multiple births in neonatal and perinatal trials: systematic review and case study, J. Pediatr. 156 (2) (2010) 202-208.

[21] H. Schuman, Passend Onderwijs - pas op de plaats of stap vooruit? Tijdschr. Orthop. 46 (2007) 267-280.

[22] G. Driessen, L. Mulder, B. Leest, T. Verrijt, Zittenblijven in Nederland: een probleem? Tijdschr. Orthop. 53 (2014) 297-311.

[23] V. Simms, et al., Mathematics difficulties in extremely preterm children: evidence of a specific deficit in basic mathematics processing, Pediatr. Res. 73 (2) (2013) $236-244$.

[24] C.S.H. Aarnoudse-Moens, et al., Executive function and IQ predict mathematical and attention problems in very preterm children, PLoS One (8) (2013) 2.

[25] G. Stoet, D.C. Geary, Sex differences in mathematics and reading achievement are inversely related: within- and across-nation assessment of 10 years of PISA data, PLoS One 8 (3) (2013). 
[26] A. Ardila, et al., The influence of the parents' educational level on the development of executive functions, Dev. Neuropsychol. 28 (1) (2005) 539-560.

[27] C.S.H. Aarnoudse-Moens, et al., Meta-analysis of neurobehavioral outcomes in very preterm and/or very low birth weight children, Pediatrics 124 (2) (2009) 717-728.

[28] J. van't Hooft, et al., Predicting developmental outcomes in premature infants by term equivalent MRI: systematic review and meta-analysis, Systematic Reviews (4) (2015).
[29] L.J. Woodward, et al., Neonatal MRI to predict neurodevelopmental outcomes in preterm infants, N. Engl. J. Med. 355 (7) (2006) 685-694.

[30] R.M. Joseph, et al., Neurocognitive and academic outcomes at age 10 years of extremely preterm newborns, Pediatrics 137 (4) (2016).

[31] B. Roth, et al., Intelligence and school grades: a meta-analysis, Intelligence 53 (2015) 118-137. 